\title{
Development, evaluation, and influence of formulation and process variables on in vitro performance of oral elementary osmotic device of atenolol
}

\author{
N. Arjun, D. Narendar, K. Sunitha, K. Harika, B. Nagaraj \\ Department of Pharmaceutics, University College of Pharmaceutical Sciences, Kakatiya University, Warangal, Telangana, India
}

\begin{abstract}
Purpose: Osmotic devices are the most promising strategy-based systems for controlled drug delivery. By optimizing formulation and processing parameters, possible to develop osmotic systems to deliver drugs at predetermined rate with high in vitro-in vivo correlation. The aim of the present investigation was to develop an oral elementary osmotic pump (EOP) of atenolol with zero-order or near zero-order drug release profile. Materials and Methods: Differential scanning calorimetry and Fourier transform-infrared spectroscopy studies did not show any evidence of interaction between the drug and excipients. Formulations were prepared by wet granulation method and coated with cellulose acetate (CA)/ethyl cellulose containing varying amounts of dibutyl phthalate (DBP)/poly (ethylene glycol)- 400 as a plasticizer. The effect of different formulation variables on drug release: type and concentration of osmogen and plasticizer, size of the delivery orifice, nature of the rate controlling membrane, and membrane weight gain were studied. The release studies also compared with marketed immediate release formulation. Results: Formulations containing $\mathrm{NaCl}$, mannitol, and combination of both as osmogens in the drug:osmogen ratio of 1:3 and 1:4 showed zero-order drug release. Marketed tablet releases more than $95 \%$ drug in different media in $90 \mathrm{~min}$. The $4 \%$ CA in acetone with DBP as a plasticizer (at a concentration of $15 \% \mathrm{w} / \mathrm{w}$ of polymer), with orifice diameter $565 \mu \mathrm{m}$, and $8.05 \%$ increase in weight on coating were found to control the drug release independent of $\mathrm{pH}$ and agitational intensity. The formulations were stable for 3 months as per the International Council for Harmonisation guidelines. Conclusion: Atenolol containing EOPs and process parameters on release studies were studied and confirmed based on osmotic technology.
\end{abstract}

Key words: Atenolol, drug release, elementary osmotic pump, formulation variables, marketed tablet, osmogen

\section{INTRODUCTION}

To overcome multiple daily dosing problems, controlled release (CR) and sustained release (SR) delivery systems are receiving considerable attention from pharmaceutical industries worldwide. Various SR and CR drug delivery systems suffer from certain disadvantages such as decreased systemic availability in comparison to immediate release conventional dosage forms due to incomplete release, increased first-pass

\section{Address for correspondence:}

Asst. Prof. B. Nagaraj,

Department of Pharmaceutics, University College of Pharmaceutical Sciences, Kakatiya University, Warangal - 506 009, Telangana, India. E-mail: arjunnarala05@gmail.com

\begin{tabular}{|l|l|}
\hline \multicolumn{2}{|c|}{ Access this article online } \\
\hline Quick Response Code: & Website: \\
\hline & www.jpionline.org \\
\cline { 2 - 2 } & DOI: \\
\hline
\end{tabular}

metabolism, increased instability, insufficient residence time for complete release, site-specific absorption, and $\mathrm{pH}$-dependent solubility. In addition, factors such as $\mathrm{pH}$, presence of food, and other physiological factors may affect drug release from these systems. One of the Novel Drug Delivery Systems that can overcome the limitations of sustained and controlled drug delivery systems is Osmotically Controlled Drug Delivery Systems. Osmotic systems utilize the principles of osmotic pressure for the delivery of drugs. ${ }^{[1]}$ Oral osmotically CR delivery system provides a uniform concentration/amount of drug at the site of absorption and thus after absorption, allow

This is an open access article distributed under the terms of the Creative Commons Attribution-NonCommercial-ShareAlike 3.0 License, which allows others to remix, tweak, and build upon the work non-commercially, as long as the author is credited and the new creations are licensed under the identical terms.

For reprints contact: reprints@medknow.com

How to cite this article: Arjun N, Narendar D, Sunitha K, Harika K, Nagaraj B. Development, evaluation, and influence of formulation and process variables on in vitro performance of oral elementary osmotic device of atenolol. Int J Pharma Investig 2016;6:238-46. 
maintenance of plasma concentration within therapeutic range, which minimizes side effects and also reduces the frequency of administration. ${ }^{[2]}$ Drug release from these systems is independent of $\mathrm{pH}$ and other physiological parameters to a large extent and it is possible to modulate the release characteristics by optimizing the properties of drug and system. ${ }^{[3]}$ Osmotic pumps can be used as experimental tools to determine important pharmacokinetic parameters of new or existing drugs. ${ }^{[4]}$ At the same time, they can also be utilized to deliver drugs at a controlled and predetermined rate..$^{[5-7]}$

Atenolol is a selective $\beta_{1}$ receptor antagonist, belonging to the group of $\beta$-blockers, a class of drugs used primarily in cardiovascular diseases. ${ }^{\left[{ }^{8,9]}\right.}$ The absorption of atenolol upon oral administration is rapid but incomplete, due to incomplete intestinal absorption; the systemic bioavailability is about $40 \%-50 \%$. Administration of conventional atenolol tablets has been reported to exhibit fluctuations in plasma drug levels, resulting in side effects such as hypopiesia, bradycardia, dizziness, and gastrointestinal (GI) upset. ${ }^{[10]}$

Therefore, the development of oral osmotic drug delivery systems for atenolol is essential for maintaining constant blood levels for a prolonged period of time without adverse effects associated with frequent oral administration. The present study was aimed toward the development of SR formulations of atenolol based on osmotic technology. Different formulation variables were studied and optimized to achieve the desired drug release profile.

\section{MATERIALS AND METHODS}

\section{Materials}

Atenolol was gift sample from Smruthi Organics Pvt. Ltd., Hyderabad, India. $\mathrm{NaCl}$, mannitol, dicalcium phosphate, magnesium stearate, talc, hydrochloric acid, and sodium hydroxide were purchased from S.D. Fine Chemicals, Mumbai, India. PVP k-30 was purchased from Himedia Laboratories Ltd., Mumbai, India. Cellulose acetate (CA) was a gift sample from AET Pharma, Hyderabad, India. Ethyl cellulose, HPMC $\mathrm{K}_{4} \mathrm{M}$, and dibutyl phthalate (DBP) were gift samples from Dr. Reddy's Laboratories, Hyderabad, India. Acetone, isopropyl alcohol, and poly (ethylene glycol) (PEG)-400 were purchased from Merck Ltd., Hyderabad, India. All chemicals and reagents used were of analytical or pharmacopoeial grade.
Formulation development

Fourier transform-infrared spectroscopy and differential scanning calorimetry studies

Compatibility of atenolol with different excipients was tested using the techniques of differential scanning calorimetry (DSC) and Fourier transform-infrared spectroscopy analysis of pure drug and optimized formulations. ${ }^{[1]}$ The DSC curves of the samples were obtained by a differential scanning calorimeter (DSC 823e, Mettler-Toledo, Columbus, OH, USA). Average sample weight of $5 \pm 2 \mathrm{mg}$ was heated in hermetically sealed aluminum pan over a temperature range of $20^{\circ} \mathrm{C}-300^{\circ} \mathrm{C}$ under a constant nitrogen gas flow of $30 \mathrm{~mL} / \mathrm{min}$ at a heating rate of $10^{\circ} \mathrm{C} / \mathrm{min}$. The instrument was calibrated with indium (calibration standard, purity $>99.9 \%$ ) for melting point and heat of fusion.

\section{Preparation of core tablets}

Core tablets of atenolol were prepared by wet granulation method. $\mathrm{NaCl}$ with higher osmotic pressure of $356 \mathrm{~atm}$ and mannitol with a lower osmotic pressure of $38 \mathrm{~atm}$ were chosen as osmogens to prepare various formulations. Atenolol was blended with other ingredients after passing $\mathrm{NaCl}$ through \# 100-mesh, other excipients through \# 40-mesh. The blend was mixed for $10 \mathrm{~min}$ and PVP k-30 was added. The mixture was granulated with water and the resulting wet mass passed through \# 18-mesh. The granules were dried at $55^{\circ} \mathrm{C}$ after which they were passed through \# 25-mesh. These sized granules were then blended with \# 60-mesh passed magnesium stearate and talc, compressed into tablets having an average weight of $300 \mathrm{mg}$ using 16 station rotary tablet compression machine (Riddhi, Ahmedabad, India) fitted with $8 \mathrm{~mm}$ round standard concave punches. Formulae of different core formulations of atenolol are listed in Table 1.

\section{Coating of core tablets}

The core tablets of atenolol were coated in a coating pan (VJ Instruments, Hyderabad, India). The composition of coating solution used for coating of atenolol core tablets is given in Table 2. Various components of the coating solution were added to the solvent mixture in a sequential manner. Core tablets of atenolol were placed in the coating pan along with $200 \mathrm{~g}$ of filler tablets. Initially, pan was rotated at low speed $(2-5 \mathrm{rev} / \mathrm{min})$ and heated air was passed through the tablet bed. Coating process was started once the outlet air temperature reached $28^{\circ} \mathrm{C}$. The revolutions per minute of the pan were kept in the range of 23-27 and coating solution was sprayed at the rate of $1-2 \mathrm{~mL} / \mathrm{min}$. Atomization pressure was kept at $1 \mathrm{~kg} / \mathrm{cm}^{2}$ and

\begin{tabular}{|c|c|c|c|c|c|c|c|c|c|c|c|c|c|c|c|}
\hline Ingredients & FA1 & FA2 & FA3 & FA4 & FA5 & FA6 & FA7 & FA8 & FA9 & FA10 & FA11 & FA12 & FA13 & FA14 & FA15 \\
\hline Atenolol & 50 & 50 & 50 & 50 & 50 & 50 & 50 & 50 & 50 & 50 & 50 & 50 & 50 & 50 & 50 \\
\hline $\mathrm{NaCl}$ & - & 12.5 & 25 & 37.5 & 50 & 100 & 150 & 200 & - & - & - & - & 50 & 50 & 50 \\
\hline Mannitol & - & - & - & - & - & - & - & - & 50 & 100 & 150 & 200 & 50 & 100 & 150 \\
\hline DCP & 232.5 & 220 & 207.5 & 195 & 182.5 & 132.5 & 82.5 & 32.5 & 182.5 & 132.5 & 82.5 & 32.5 & 132.5 & 82.5 & 32.5 \\
\hline PVP-K 30 & 7.5 & 7.5 & 7.5 & 7.5 & 7.5 & 7.5 & 7.5 & 7.5 & 7.5 & 7.5 & 7.5 & 7.5 & 7.5 & 7.5 & 7.5 \\
\hline Talc & 5 & 5 & 5 & 5 & 5 & 5 & 5 & 5 & 5 & 5 & 5 & 5 & 5 & 5 & 5 \\
\hline Mg.st & 5 & 5 & 5 & 5 & 5 & 5 & 5 & 5 & 5 & 5 & 5 & 5 & 5 & 5 & 5 \\
\hline
\end{tabular}

All ingredients weighed in $\mathrm{mg}$ 


\begin{tabular}{lccccc} 
Table 2: Composition of coating solution \\
\hline Ingredients & A & B & C & D & E \\
\hline Cellulose acetate $(\mathrm{g})$ & 4 & 4 & 4 & - & - \\
Ethyl cellulose $(\mathrm{g})$ & - & - & - & 5 & 5 \\
PEG-400 (\%w/w of polymer) & 15 & - & - & 10 & - \\
DBP (\%w/w of polymer) & - & 10 & 15 & - & 15 \\
HPMC (g) & - & - & - & 2 & 2 \\
Acetone (ml) & 95.4 & 95.6 & 95.4 & - & - \\
IPA (ml) & - & - & - & 93.6 & 93.4 \\
\hline
\end{tabular}

PEG-400: Polyethylene glycol 400, DBP: Dibutylphthalate, HPMC: Hydroxypropyl methyl cellulose, IPA: Isopropyl alcohol

the outlet temperature was maintained above $28^{\circ} \mathrm{C}$ by keeping the inlet air temperature in the range of $50^{\circ} \mathrm{C}-55^{\circ} \mathrm{C}$. Coating was continued until desired weight gain was obtained on the active tablets and was dried at room temperature for $24 \mathrm{~h}$, before further evaluation.

\section{Drilling of coated tablets}

For coated tablets, a small orifice was drilled through the one side by standard mechanical micro drills with various diameters (ranging from 480 to $700 \mu \mathrm{m}$ ). After drilling, the orifice size was controlled and measured microscopically (BAUSH and LOMB, Balplan microscope, USA) to make sure the right orifice size was used for dissolution studies. Any deviation in orifice size by more than $10 \mu \mathrm{m}$ from the target orifice size was rejected and not used in dissolution studies. ${ }^{[12]}$

\section{Evaluation of the developed formulations Evaluation of core tablets \\ Flow properties}

To determine bulk and tapped density of the granules, on a tap density tester (ETD-1020, Electrolab, Hyderabad, India) was used. From the data obtained, compressibility index, Hausner ratio, and angle of repose were calculated. ${ }^{[13]}$

\section{Physiochemical properties}

The prepared core tablets are evaluated for weight variation, thickness, hardness, and friability. The weights and thickness of twenty core tablets of atenolol were measured using digital balance (Denver, Germany) and a digital screw gauge (Mitutoyo, Japan), respectively. The hardness of core tablets was measured by Pfizer hardness tester and results were expressed in $\mathrm{kg} / \mathrm{cm}^{2}$. Friability is a measure of mechanical strength of tablets. Roche friabilator (Electrolab, Mumbai, India) was used to determine the friability. The average values, standard deviation, and relative standard deviation were calculated.

\section{Determination of drug content}

Twenty uncoated tablets were taken and powdered; powder equivalent to one tablet was taken and was allowed to dissolve in $100 \mathrm{~mL}$ of distilled water on a rotary shaker overnight. The solution was centrifuged and the supernatant was filtered through $0.22 \mu$ membrane filter. The absorbance of filtrate was measured using an ultraviolet-visible spectrophotometer (Elico SL-159, Hyderabad, India) at $226 \mathrm{~nm}$ against distilled water as blank.

\section{Evaluation of coated tablets Weight and thickness variation, hardness of coated tablets}

Twenty coated tablets were taken and their weight calculated individually and collectively on a digital weighing balance. Average weight was calculated along with percentage increase in weight. The increase in thickness upon coating was determined using digital screw gauge. Hardness of each batch of formulation was determined using Pfizer hardness tester and the average was calculated.

\section{Determination of aperture diameter}

After drilling, the orifice size was controlled and measured microscopically to make sure the right orifice size was used for dissolution studies. Any deviation in orifice size by more than $10 \mu \mathrm{m}$ from the target orifice size was rejected and not used in dissolution studies.

\section{In vitro release studies}

The developed formulations of atenolol elementary osmotic pumps (EOPs) were subjected to in vitro drug release studies using USP-II dissolution apparatus (Disso 2000, Laboratory India, Hyderabad, India) at 50 and $100 \mathrm{rev} / \mathrm{min}$. Dissolution media used were $900 \mathrm{~mL}$ of distilled water and $0.1 \mathrm{~N} \mathrm{HCl}$ for the first $2 \mathrm{~h}$ followed by $900 \mathrm{~mL}$ of phosphate buffer $\mathrm{pH} 6.8$ for the remaining $10 \mathrm{~h}$, maintained at a temperature of $37 \pm 0.5^{\circ} \mathrm{C}$. The samples were withdrawn $(5 \mathrm{~mL})$ at different time intervals and replaced with an equivalent amount of fresh medium. The dissolution samples were analyzed by UV-visible spectrophotometry at $226 \mathrm{~nm}$ (Elico, SL-159 India). ${ }^{[14]}$ Simultaneously, the in vitro release studies of marketed tablet of atenolol immediate release tablet (Aten ${ }^{\circledR}-50$ ) were conducted in $0.1 \mathrm{~N} \mathrm{HCl}, \mathrm{pH} 4.5$ buffer, and $\mathrm{pH} 7.4$ phosphate buffer.

\section{Dissolution profile modeling}

Dissolution data of the optimized formulations were fitted to various mathematical models (zero-order, first-order, Higuchi, and Korsmeyer-Peppas) ${ }^{[15-18]}$ to describe the kinetics of drug release. Goodness-of-fit test $\left(R^{2}\right)$ was taken as a criterion for selecting the most appropriate model.

\section{Burst strength}

Burst strength of the exhausted shells, after $12 \mathrm{~h}$ of dissolution, was determined to assure that the tablets would maintain their integrity in the gastro intestinal tract (GIT). Burst strength was determined as the force required to break/rupture the shells after dissolution studies. Ultratest tensile tester, Mecmesin, UK with a $5 \mathrm{~kg}$ load cell was utilized for this purpose. Test speed of $0.8 \mathrm{~mm} / \mathrm{s}$ was selected and the distance moved was set at $2 \mathrm{~mm}$.

\section{Effect of formulation variables on in vitro drug release}

Various formulation factors such as nature of semipermeable membrane forming polymer, type and concentration of plasticizer, percentage increase in weight upon coating, and aperture diameter affect the drug release from an EOP. The 
effect of formulation variables on in vitro drug release kinetics is studied by varying the above listed factors. The influence of $\mathrm{pH}$ and agitational intensity on release kinetics was studied by conducting the drug release in varying conditions of $\mathrm{pH}$ and agitational intensity.

\section{RESULTS AND DISCUSSION}

Drug-excipient compatibility studies by differential scanning calorimetry and Fourier transform-infrared spectroscopy

The thermal properties of the drug and the mixture of drug and excipients are of important interest since this can help to assess the interaction among different components of the formulations. The DSC thermogram of pure drug [Figure 1] showed an endothermic peak (broader) at $158.78^{\circ} \mathrm{C}$ in a melting range of $156-160^{\circ} \mathrm{C}$. The DSC thermograms of optimized formulation FA8 and FA12 showed an endothermic peak of drug at $157.74^{\circ} \mathrm{C}$ and $157.87^{\circ} \mathrm{C}$ which was well preserved with slight change in terms of broadening of peak toward the higher temperature. From the results, it was concluded that the drug had the compatibility with polymers and other excipients used in the formulation.

Atenolol showed characteristic bands at 3342.05 due to $\mathrm{O}-\mathrm{H}$ (stretching), 3014.22 due to $\mathrm{C}-\mathrm{H}$ aromatic (stretching), 2870.16 due to $\mathrm{C}-\mathrm{H}$ (stretching), 1401.11 due to $\mathrm{C}=\mathrm{C}$ aromatic (stretching), and $1421.05 / \mathrm{cm}$ due to $\mathrm{CH}_{2}$ (bending). Similar patterns were observed in optimized formulations (FA* and FA12), but there was a slight shift in the absorption spectrum of the drug, and it indicates that there was no interaction between the drug and excipients [Figure 2].

\section{Determination of flow properties of core tablets}

Various properties of granules such as bulk density, tap density, Carr's Index, Hausner ratio, and angle of repose were determined. The bulk density and tapped density of the granules

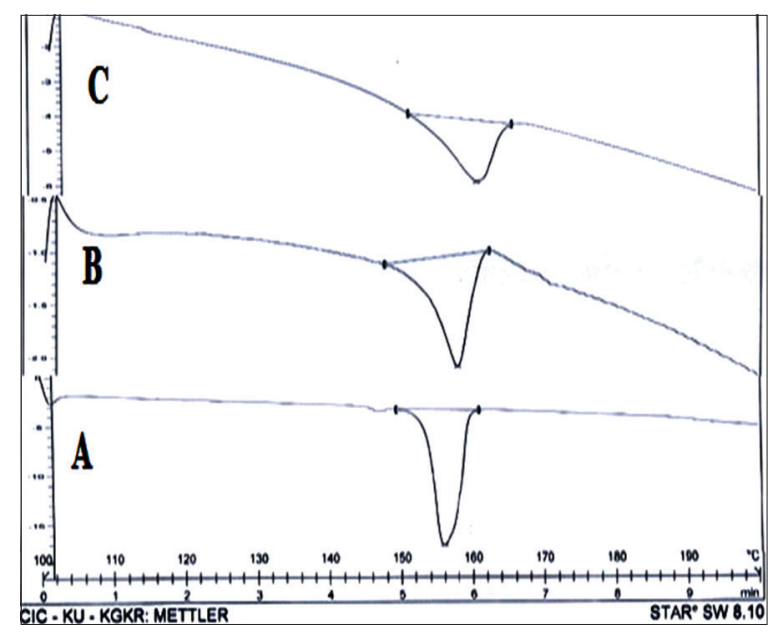

Figure 1: Differential scanning calorimetry curves for studying drug-excipient compatibility (A) pure drug, (B) formulation FA8, (C) formulation FA12 were found to be in the range of $0.48-0.53$ and $0.53-0.58$, respectively. Carr's index of the granules ranged from 7.27 to 12.28 showing the granules is freely flowing (confidence interval $=5-12$ indicating freely flowing granules). Hausner ratio of granules was found to be in the range of 0.88-0.92 (heart rate $=0-1.2$ indicating free flowing property). The angle of repose of granules of all the formulations was found to be $\leq 30^{\circ}$, hence are freely flowing. Various process parameters such as weight variation, hardness, thickness, friability, and content uniformity of the core tablets were evaluated and were found to be within the limits as per USP specifications. The results were shown in Table 3.

\section{Evaluation of coated tablets}

Coated tablets were evaluated for their thickness, hardness, and orifice diameter and the results are presented in Table 3. On $8 \%$ increase in weight on coating, there was an increase of $0.3-0.5 \mathrm{~mm}$ increase in thickness and hardness increased from $6 \mathrm{~kg} / \mathrm{cm}^{2}$ to around $13.67 \mathrm{~kg} / \mathrm{cm}^{2}$ on an average. Aperture diameters were found to range from $557 \mu \mathrm{m}$ to $571 \mu \mathrm{m}$.

\section{In vitro drug release}

The cumulative percentage drug release profiles from various formulations of EOP containing $\mathrm{NaCl}$, mannitol, and combination of $\mathrm{NaCl}$ and mannitol as osmogens, coated with $4 \%$ CA solution with dibutyl phthalate ( $15 \%$ of CA) as a plasticizer in acetone up to $8.05 \%$ increase in weight of core tablet are represented in Figure 3.

It is evident from the drug release, formulations without osmogen (FA1) were incomplete with $88.12 \%$ of drug release in $24 \mathrm{~h}$ dissolution. Formulations containing $\mathrm{NaCl}$ as osmogen at the drug:osmogen ratio of 1:0.25, 1:0.5, 1:0.75, 1:1, and $1: 2$ released $99.67 \%, 89.69 \%, 98.09 \%, 97.53 \%$, and $98.36 \%$ of drug, respectively, in controlled pattern up to $24 \mathrm{~h}$. Formulations containing $\mathrm{NaCl}$, at a drug:osmogen ratio of $1: 3$ and $1: 4$ released $99.65 \%$ and $98.65 \%$ of drug, respectively, in $24 \mathrm{~h}$.

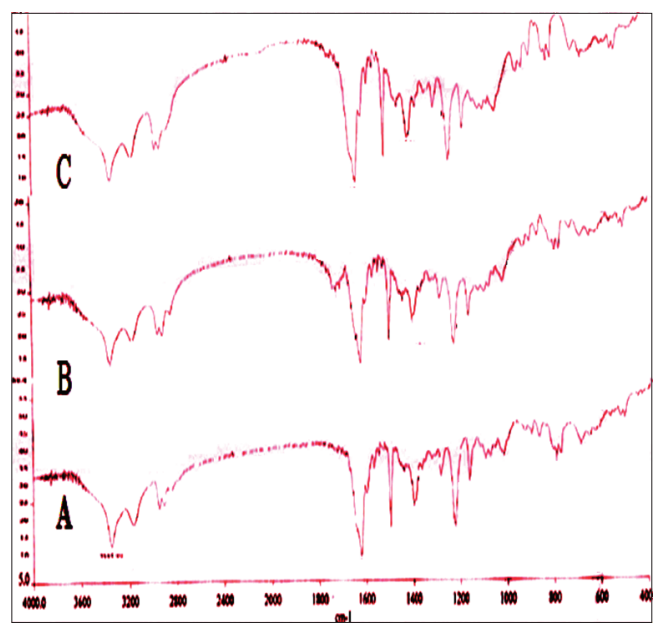

Figure 2: Fourier transform-infrared spectroscopy spectra for studying drug-excipient compatibility (A) pure drug, (B) formulation FA8, and (C) formulation FA12 
Arjun, et al.: Atenolol elementary osmotic systems

Table 3: Evaluation of core and coated tablets

\begin{tabular}{|c|c|c|c|c|c|c|c|c|}
\hline \multirow[t]{2}{*}{ Formulation } & \multicolumn{5}{|c|}{ Core tablets } & \multicolumn{3}{|c|}{ Coated tablets } \\
\hline & $\begin{array}{c}\text { Weight } \\
\text { variation }\end{array}$ & Thickness (mm) & $\begin{array}{c}\text { Hardness } \\
\left(\mathrm{kg} / \mathrm{cm}^{2}\right)\end{array}$ & Friability (\%) & $\begin{array}{c}\text { Content } \\
\text { uniformity }\end{array}$ & Thickness & Hardness & $\begin{array}{c}\text { Orifice } \\
\text { diameter }(\mu \mathrm{m})\end{array}$ \\
\hline FT1 & $305.22 \pm 1.21$ & $4.76 \pm 0.03$ & $7.20 \pm 0.5$ & 0.12 & 98.23 & $5.16 \pm 0.03$ & $13.2 \pm 0.6$ & $565 \pm 13$ \\
\hline FT1 & $310.12 \pm 3.45$ & $4.81 \pm 0.03$ & $6.30 \pm 0.5$ & 0.09 & 99.65 & $5.21 \pm 0.02$ & $14.0 \pm 0.5$ & $571 \pm 10$ \\
\hline FT3 & $307.80 \pm 2.63$ & $4.80 \pm 0.05$ & $7.50 \pm 0.5$ & 0.11 & 99.12 & $5.26 \pm 0.04$ & $12.9 \pm 1.6$ & $559 \pm 16$ \\
\hline FT4 & $296.09 \pm 2.43$ & $4.87 \pm 0.04$ & $6.30 \pm 0.5$ & 0.08 & 98.44 & $5.17 \pm 0.04$ & $15.2 \pm 0.3$ & $571 \pm 11$ \\
\hline FT5 & $292.05 \pm 4.23$ & $4.79 \pm 0.08$ & $7.40 \pm 0.5$ & 0.14 & 99.23 & $5.09 \pm 0.06$ & $12.6 \pm 0.8$ & $560 \pm 19$ \\
\hline FT6 & $282.37 \pm 3.45$ & $4.85 \pm 0.05$ & $6.50 \pm 0.5$ & 0.11 & 98.63 & $5.15 \pm 0.05$ & $13.5 \pm 0.4$ & $565 \pm 15$ \\
\hline FT7 & $283.09 \pm 4.63$ & $4.82 \pm 0.06$ & $6.50 \pm 0.5$ & 0.10 & 99.65 & $5.28 \pm 0.04$ & $12.8 \pm 0.9$ & $558 \pm 21$ \\
\hline FT8 & $293.65 \pm 2.12$ & $4.83 \pm 0.04$ & $7.80 \pm 0.5$ & 0.13 & 98.65 & $5.03 \pm 0.06$ & $13.1 \pm 1.5$ & $561 \pm 14$ \\
\hline FT9 & $284.15 \pm 4.75$ & $4.79 \pm 0.06$ & $7.50 \pm 0.5$ & 0.12 & 98.45 & $5.19 \pm 0.05$ & $13.8 \pm 1.1$ & $568 \pm 12$ \\
\hline FT10 & $274.50 \pm 2.52$ & $4.82 \pm 0.05$ & $6.50 \pm 0.5$ & 0.15 & 99.64 & $5.22 \pm 0.05$ & $12.9 \pm 1.5$ & $557 \pm 17$ \\
\hline FT11 & $301.50 \pm 4.39$ & $4.86 \pm 0.04$ & $6.70 \pm 0.5$ & 0.14 & 98.12 & $5.16 \pm 0.04$ & $13.9 \pm 1.2$ & $564 \pm 15$ \\
\hline FT12 & $305.50 \pm 4.35$ & $4.80 \pm 0.04$ & $6.60 \pm 0.5$ & 0.09 & 99.72 & $5.13 \pm 0.07$ & $14.0 \pm 0.9$ & $559 \pm 13$ \\
\hline FT13 & $311.45 \pm 2.12$ & $4.77 \pm 0.08$ & $7.00 \pm 0.5$ & 0.12 & 97.13 & $5.07 \pm 0.08$ & $12.6 \pm 0.8$ & $563 \pm 16$ \\
\hline FT14 & $318.33 \pm 1.45$ & $4.86 \pm 0.03$ & $6.50 \pm 0.5$ & 0.13 & 99.12 & $5.16 \pm 0.05$ & $13.2 \pm 1.5$ & $556 \pm 16$ \\
\hline FT15 & $285.80 \pm 1.63$ & $4.85 \pm 0.04$ & $7.40 \pm 0.5$ & 0.09 & 98.45 & $5.15 \pm 0.06$ & $13.8 \pm 1.2$ & $564 \pm 15$ \\
\hline
\end{tabular}

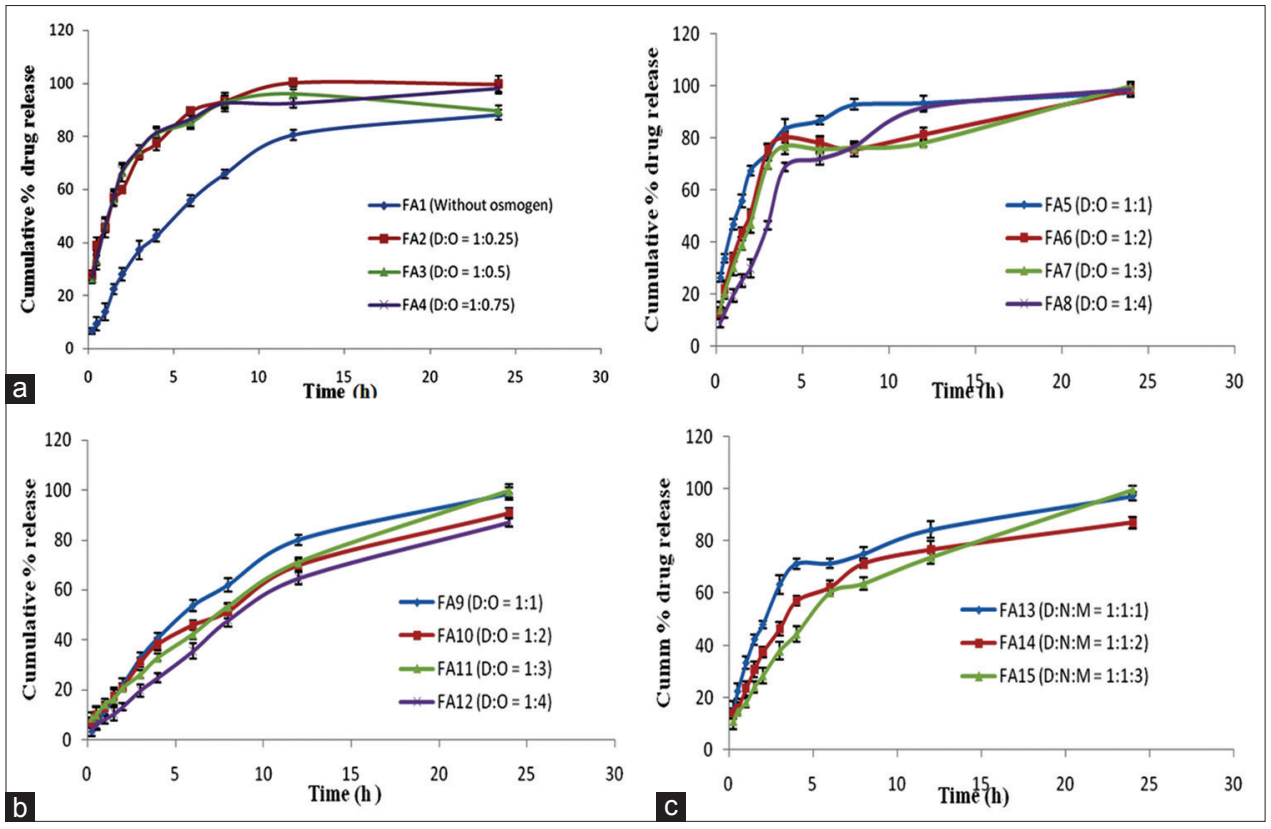

Figure 3: In vitro drug release profile of atenolol elementary osmotic pumps containing (a) $\mathrm{NaCl}$ as osmogen, (b) mannitol as osmogen, and (c) combination of $\mathrm{NaCl}$ and mannitol as osmogens (mean \pm standard deviation, $n=3$ )

Formulations with mannitol alone as osmogen, i.e., formulations FA9, FA10, FA11, and FA12 released 98.53\%, 90.68\%, 99.57\%, and $87.02 \%$ of drug in $24 \mathrm{~h}$ in a controlled fashion. The drug release from FA12 was incomplete, but the drug release followed zero-order for $12 \mathrm{~h}$. From the marketed immediate release tablets, it was found that about $93.99 \% \pm 1.32 \%, 92.06 \% \pm 1.95 \%$, and $101.4 \% \pm 2.47 \%$ drug was released in $90 \mathrm{~min}$ in $\mathrm{pH} 1.2, \mathrm{pH} 4.5$, and pH 6.8 buffers, respectively, and shown in Figure 4.

FA13, FA14, and FA15 were formulated with a combination of both $\mathrm{NaCl}$ and mannitol as osmogens and found to release $97.13 \%, 87.02 \%$, and $99.57 \%$ of drug, respectively, in $24 \mathrm{~h}$.

\section{Dissolution profile modeling}

From in vitro drug release profile and $R^{2}$ values, it was found that the drug release from formulations without osmogen (FA1) was incomplete and was released by Higuchi kinetics governed by non-Fickian diffusion with an " $n$ " value of 0.6826 [Table 4]. Formulations containing $\mathrm{NaCl}$ as osmogen with a drug:osmogen ratio of 1:0.25, 1:0.5, 1:0.75, and 1:1 (FA2, FA3, FA4, and FA5) showed drug release by Higuchi (FA2 and FA5) and Korsmeyer and Peppas (FA3 and FA4) release kinetics, rather than by zero-order kinetics governed by Fickian diffusion with “ $n$ " values of $0.3581,0.4385,0.4372$, and 0.4343 , respectively. Formulations containing drug:osmogen in the ratio of 1:2 (FA6) showed drug release by Korsmeyer and Peppas kinetics with the major mechanism of drug release being non-Fickian diffusion $(n=0.6758)$. The formulations with drug:osmogen in the ratio of $1: 3$ and $1: 4$ (FA7 and FA8), released $69.73 \%$ and $46.36 \%$ of drug, respectively, in zero-order for a period of 3 h by non-Fickian diffusion mechanism having " $n$ " values of 0.6212 and 0.6382 , respectively. 
Table 4: Correlation coefficient $\left(\mathrm{R}^{2}\right)$ of different kinetic models for various formulations

\begin{tabular}{|c|c|c|c|c|c|c|c|}
\hline \multirow[t]{2}{*}{ Formulation } & \multirow[t]{2}{*}{$\%$ Drug release } & \multirow[t]{2}{*}{ Time (hrs) } & \multicolumn{4}{|c|}{$\mathbf{R}^{2}$ value } & \multirow[t]{2}{*}{$n$} \\
\hline & & & Zero-order & $\begin{array}{l}\text { First } \\
\text { order }\end{array}$ & Higuchi & $\begin{array}{c}\text { Kores } \\
\text { meyer- Peppas }\end{array}$ & \\
\hline FA1 & 55.78 & 3 & 0.9504 & 0.9392 & 0.9961 & 0.9909 & 0.6826 \\
\hline FA2 & 72.88 & 3 & 0.9637 & 0.9944 & 0.9900 & 0.9892 & 0.3581 \\
\hline FA3 & 74.99 & 3 & 0.9526 & 0.9691 & 0.9925 & 0.9939 & 0.4385 \\
\hline FA4 & 75.31 & 3 & 0.9519 & 0.8888 & 0.9908 & 0.9929 & 0.4372 \\
\hline FA5 & 74.26 & 3 & 0.9946 & 0.8521 & 0.9981 & 0.9934 & 0.4343 \\
\hline FA6 & 75.41 & 3 & 0.9913 & 0.9008 & 0.9778 & 0.9949 & 0.6758 \\
\hline FA7 & 69.73 & 3 & 0.9964 & 0.9103 & 0.9657 & 0.9882 & 0.6212 \\
\hline FA8 & 46.36 & 3 & 0.9931 & 0.9864 & 0.9565 & 0.9854 & 0.6382 \\
\hline FA9 & 80.01 & 12 & 0.9621 & 0.9806 & 0.9944 & 0.9940 & 0.8349 \\
\hline FA10 & 64.83 & 12 & 0.9633 & 0.9971 & 0.9895 & 0.9908 & 0.6207 \\
\hline FA11 & 70.99 & 12 & 0.9941 & 0.9039 & 0.9761 & 0.9720 & 0.5575 \\
\hline FA12 & 64.59 & 12 & 0.9974 & 0.9967 & 0.9610 & 0.9802 & 0.7316 \\
\hline FA13 & 63.25 & 3 & 0.9837 & 0.9652 & 0.9963 & 0.9990 & 1.1308 \\
\hline FA14 & 57.00 & 4 & 0.9913 & 0.9118 & 0.9858 & 0.9759 & 0.5297 \\
\hline FA15 & 60.30 & 6 & 0.9949 & 0.9230 & 0.9790 & 0.9759 & 0.5365 \\
\hline
\end{tabular}

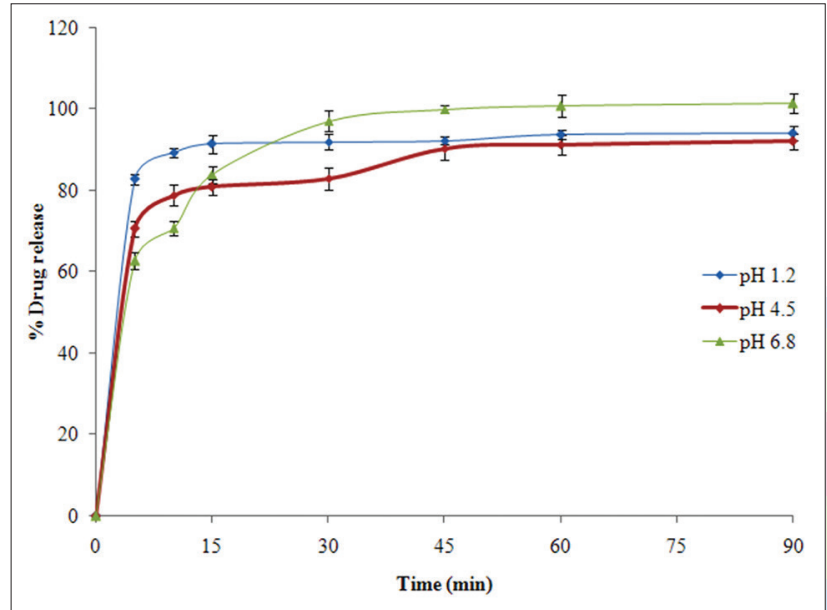

Figure 4: In vitro drug release from atenolol immediate release marketed tablets (aten-50) (mean \pm standard deviation, $n=3$ )

Formulation FA9 released drug by Higuchi kinetics and the drug transport involves non-Fickian diffusion mechanism $(n=0.8349)$. Drug release from formulation FA10 is found to follow first-order release kinetics with non-Fickian mechanism of drug transport with an " $n$ " value of 0.6207 . Zero-order drug release was found with formulations FA11 and FA12 for which mechanism of drug release being non-Fickian diffusion $(n=0.5575$ and 0.7316$)$ for a period of $12 \mathrm{~h}$ releasing $70.99 \%$ and $64.59 \%$, respectively.

It is clearly evident from the dissolution profiles and $R^{2}$ values that the zero-order drug release was observed from formulation when the drug:osmogen ratio is $1: 3$ or $1: 4 . \mathrm{NaCl}$ as osmogen released drug in zero-order pattern only for a period of $3 \mathrm{~h}$. The reason could be attributed to the higher osmotic pressure of the $\mathrm{NaCl}$ (356 atm). Formulations with mannitol alone as osmogens showed zero-order drug release for a period of $12 \mathrm{~h}$. The reason could be attributed to the lower osmotic pressure of the mannitol $(38 \mathrm{~atm})$. Formulations with a combination of $\mathrm{NaCl}$ and mannitol showed drug release for a period of $4-6 \mathrm{~h}$ as it includes both $\mathrm{NaCl}$ (higher osmotic pressure) and mannitol (lower osmotic pressure). Therefore, mannitol with an osmotic pressure of $38 \mathrm{~atm}$ was chosen as osmogen which released greater percentage of labeled amount of drug in zero-order.

\section{Burst strength}

The strength of mechanical destructive forces in the GIT of humans has been reported to be $1.9 \mathrm{~N}$ (approximately $190 \mathrm{~g}$ ). ${ }^{[19]}$ With percentage increase in the weight upon coating of the EOP, there was increase in burst strength of the emptied tablets. As the percentage increase in weight increased from $2 \%$ to $8.05 \%$, burst strength increased from 1.56 to $8.83 \mathrm{~N}$. It was found that burst strength of all the formulations was more than the hydrodynamic pressure of the GIT $(1.86 \mathrm{~N})$. Hence, the EOPs are expected to remain intact in GIT and in in vitro dissolution conditions.

\section{Influence of formulation parameters on drug release The effect of type and polymer concentration on the release rate from osmotic devices}

To select suitable polymer(s) for the formulation of osmotic devices, various semi-permeable membrane-forming polymers were incorporated in the coating solution. Ethyl cellulose is completely impermeable to water. ${ }^{[20,21]}$

Ethyl cellulose (5\%) (18-22 cps) dissolved in isopropyl alcohol was used as a coating solution with DBP $(15 \%$ w/w of ethyl cellulose) as plasticizer. The results showed that coating with ethyl cellulose showed dose dumping after $4 \mathrm{~h}$ of dissolution because of the detachment of the coating. The reason may be attributed to the extreme hydrophobic surface of ethyl cellulose unable to attach to the smooth surface of atenolol core tablet. Thus, to increase the roughness of the surface and thus the adherence of ethyl cellulose, the core tablets of atenolol were coated with $3 \%$ aqueous solution of HPMC (15 cps) until $2 \%$ increase in weight of tablet was obtained. The coating remained for a period of $6 \mathrm{~h}$, and then got detached resulting in dose dumping at the end of $6^{\text {th }} \mathrm{h}$. The bust strength of the ethyl cellulose coating was not sufficient to withstand the hydrodynamic pressure of the dissolution medium, due to the formation of porous structure. 
CA films are insoluble, yet semi-permeable to allow water to pass through the tablet coating. The water permeability of CA is relatively high and can be easily adjusted by varying the degree of acetylation. The permeability of CA film can be further increased by the addition of hydrophilic flux enhancer (necessary in case of poorly water-soluble drugs). Incorporation of a plasticizer in CA coating formulation generally lowers the glass transition temperature, increases the polymer chain mobility, enhances the flexibility, and affects the permeability of the film.

CA coating remained intact even after $24 \mathrm{~h}$ of dissolution. The $4 \% \mathrm{w} / \mathrm{w}$ of $\mathrm{CA}$ in acetone had excellent spray properties. CA coating improved the elegance of osmotic pump along with controlling the release of the drug from the core formulation. The emptied tablets after 24 h of dissolution had sufficient burst strength.

\section{The effect of type and plasticizer concentration on the release rate}

Plasticizers are added to modify the physical properties and improve film-forming characteristics of polymers. ${ }^{[22]}$ As plasticizers will also affect the permeability of polymer films, it is important to investigate the effect of plasticizer on the release rate of drug from osmotic devices. Ethyl cellulose being completely impermeable to water, HPMC as water-soluble additive and hydrophilic PEG-400 as plasticizer increased the permeability of the film but decreased the burst strength of the coating. After replacing the PEG-400 with DBP, the coating remained intact for $6 \mathrm{~h}$, but there was no significant improvement in burst strength of the coating and hence got disrupted at the end of $6 \mathrm{~h}$.

The coating containing PEG-400 was found to release the drug by diffusion rather than by zero-order. As PEG-400 is a hydrophilic plasticizer, it could be leached easily and leave behind an entirely porous structure, which increases membrane permeability and thus rapid drug release.

In contrast, as DBP is insoluble in water, it is difficult to leach. Because of its hydrophobic character, the residual DBP would resist water diffusion, and as a consequence, the drug release was controlled. The more DBP incorporated into the membrane, the more difficult it was to leach, and in turn, the lower permeability of the membrane, the lower the drug release rate obtained. DBP in the concentration of $10 \%$ of CA in the coating solution formed coating which was found to be brittle with low burst strength. DBP at a concentration of $15 \% \mathrm{w} / \mathrm{w}$ of the polymer was found to form a film with good flexibility, elegant appearance, controlling the imbibitions of water from the dissolution media and thus the drug release.

\section{Type and amount of osmotically active agents}

The type and amount of osmotically active agent in the core formulation affected the drug release from osmotic devices. Atenolol being sparingly soluble does not contribute much to the osmotic pressure of the core along with the osmogens. The formulation (FA1) without osmogen showed drug release by diffusion rather than by zero-order and also the drug release was incomplete, proving the role of osmotic pressure created by the osmogen as the driving force for the drug release. $\mathrm{NaCl}$ was chosen as osmotic agent having a high osmotic pressure of $356 \mathrm{~atm}$. From the results, it is clear that the higher osmotic pressure resulting from solubilization of $\mathrm{NaCl}$ lead to the faster drug release with a zero-order only for a period of $3 \mathrm{~h}$. Mannitol with an osmotic pressure of $38 \mathrm{~atm}$ (nearly ten times less than that of $\mathrm{NaCl}$ ) was chosen as an osmogen. Formulations containing mannitol as osmogen was found to release drug in zero-order for a period of $12 \mathrm{~h}$. However, the formulations containing both the osmogens showed zero-order release for a period of $6 \mathrm{~h}$.

$\mathrm{NaCl}$, mannitol, and a combination of $\mathrm{NaCl}$ and mannitol were used in various drug:osmogen ratios. Zero-order drug release was not shown until the drug:osmogen ratio was 1:3 with both individual and combination of osmogens [Table 5]. Formulations containing $\mathrm{NaCl}$ as osmogen at a drug:osmogen ratio of 1:1, 1:2, 1:3, and 1:4 released $74.26 \%, 75.41 \%, 69.73 \%$, and $46.36 \%$ of drug, respectively, for a period of $3 \mathrm{~h}$, whereas a combination of $\mathrm{NaCl}$ and mannitol at a drug:osmogen concentration of 1:1:1, 1:1:2, and 1:1:3 released $63.25 \%, 57.00 \%$, and $60.30 \%$ of drug in 3,4 , and 6 h, respectively.

Mannitol when used alone as osmogen at a drug:osmogen concentration of $1: 1,1: 2,1: 3$, and $1: 4$ released $80.01,64.83,70.99$, and $64.59 \%$ of drug, respectively, in $12 \mathrm{~h}$.

\section{Effect of aperture diameter}

Aperture diameter is one of the critical parameters that greatly influences release rate, lag time, and release kinetics of the osmotic drug delivery devices. Thus, the size of delivery orifice must be optimized to control the drug release from osmotic systems. Formulation FA12 with mannitol at drug:osmogen ratio of $1: 4$ with aperture diameters of $480 \mu \mathrm{m}, 565 \mu \mathrm{m}$, and $700 \mu \mathrm{m}$ were subjected to dissolution. From the dissolution profiles, it was found that the drug release was not complete from the formulation with an aperture diameter of $480 \mu \mathrm{m}$. Drug release was complete from formulations with aperture diameters of 565 and $700 \mu \mathrm{m}$, but drug release followed zero-order only with an aperture diameter of $565 \mu \mathrm{m}$. No lag time was observed with all the three aperture diameters [Table 5].

\section{Effect of weight gain upon coating on in vitro drug release}

The delivery of agent from oral osmotic systems is controlled by the influx of solvent across the SPM, which in turn carries the agent to the outside environment. Water influx into EOP can be described by the following equation:

$\frac{\mathrm{dv}}{\mathrm{dt}}=\frac{\mathrm{A}}{\mathrm{h}} \mathrm{Lp}(\sigma \Delta \pi-\Delta \mathrm{p})$

Where, = water influx

$\mathrm{A}=$ membrane surface area

$\mathrm{h}=$ semi-permeable membrane thickness 
$\mathrm{Lp}=$ mechanical permeability

$\sigma=$ reflection coefficient

$\Delta \pi=$ osmotic pressure difference

$\Delta \mathrm{p}=$ hydrostatic pressure difference

Formulations with percentage increase in weight from $1.9 \%$ to $8.05 \%$ were subjected to dissolution studies. It is evident from the results that the drug was released in $<6 \mathrm{~h}$ from formulations with percentage increase in weight from $1.90 \%$ to $4.86 \%$. The reason may be attributed to nonuniform formation of coating with the resultant weak points at some places in coating through which drug might have leached. The coating with $\%$ increase in weight of $6.50 \%$ and $8.05 \%$ showed CR of drug over a period of $24 \mathrm{~h}$. Among all the formulations, formulations with $8.05 \%$ increase in weight showed zero-order drug release [Table 5].

\section{Effect of $p H$}

To study the effect of $\mathrm{pH}$ and to assure a reliable performance of the developed formulations independent of $\mathrm{pH}$, release studies of the optimized formulations were conducted according to $\mathrm{pH}$ change method. The release media used were $900 \mathrm{~mL}$ of distilled water $(\mathrm{pH} 7)$ and $900 \mathrm{~mL}$ of $0.1 \mathrm{~N} \mathrm{HCl}(\mathrm{pH}=1.2)$ for the first $2 \mathrm{~h}$ followed by $900 \mathrm{~mL}$ of phosphate buffer ( $\mathrm{pH} 6.8$ ) for the remaining $8 \mathrm{~h}$. The samples $(5 \mathrm{~mL})$ were withdrawn at predetermined intervals and analyzed using UV-visible spectrophotometer (Elico, Hyderabad, India) at $226 \mathrm{~nm}$. The results obtained showed that there was no significant difference in the cumulative percentage drug release form osmotic systems.

\section{Effect of agitational intensity}

Formulation FA12 containing mannitol as osmogen at the drug:osmogen ratio of $1: 4$, with $8 \%$ increase in weight upon coating and with an aperture diameter of $565 \mu \mathrm{m}$ were taken and subjected to in vitro dissolution at various agitational intensities. The in vitro drug release profiles at various agitation rates of 25 , 50, and $100 \mathrm{rpm}$ are presented in Figure 5. It showed that a change in agitational intensity did not significantly affect the drug release. The cumulative percentage drug release at 25, 50, and $100 \mathrm{rpm}$ was found to be $85.31 \%, 87.20 \%$, and $91.04 \%$, respectively, also performed with $75 \mathrm{rpm}$ but not observe any significant changes in the drug release $(88.88 \%$ ) and similar to that of $50 \mathrm{rpm}$. Therefore, the variations in peristaltic movements of the GI tract might not affect the drug release.

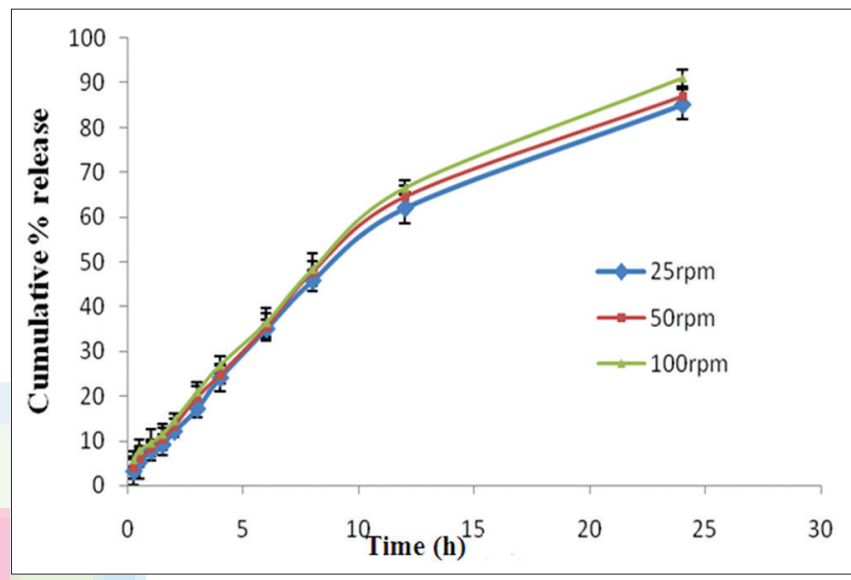

Figure 5: Effect of agitational intensity on in vitro drug release profile (mean \pm standard deviation, $n=3$ )

Table 5: Effect of type and concentration of osmogen, aperture diameter and percentage increase in weight on in-vitro drug release kinetics

\begin{tabular}{|c|c|c|c|c|c|c|}
\hline Factor & & D: O ratio & & Drug release & Kinetics & $\begin{array}{c}\text { Time of drug } \\
\text { release }\end{array}$ \\
\hline \multicolumn{7}{|l|}{ Osmogen } \\
\hline \multirow[t]{4}{*}{$\mathrm{NaCl}$} & & $1: 1$ & & 74.26 & Higuchi & 3 \\
\hline & & $1: 2$ & & 75.41 & Korsmeyer-peppas & 3 \\
\hline & & $1: 3$ & & 69.73 & Zero-order & 3 \\
\hline & & $1: 4$ & & 46.36 & Zero-order & 3 \\
\hline \multirow[t]{4}{*}{ Mannitol } & & $1: 1$ & & 80.01 & Higuchi & 12 \\
\hline & & $1: 2$ & & 64.83 & First-order & 12 \\
\hline & & $1: 3$ & & 70.99 & Zero-order & 12 \\
\hline & & $1: 4$ & & 64.59 & Zero-order & 12 \\
\hline \multirow[t]{3}{*}{$\mathrm{NaCl}+\mathrm{Mannitol}$} & & $1: 1: 1$ & & 63.25 & Korsmeyer-peppas & 3 \\
\hline & & $1: 1: 2$ & & 57 & Zero-order & 4 \\
\hline & & $1: 1: 3$ & & 60.3 & Zero-order & 6 \\
\hline \multirow[t]{2}{*}{ Aperture diameter } & Drug release & \multicolumn{4}{|c|}{$\mathbf{R}^{2}$ value } & $n$ \\
\hline & & Zero-order & First order & Higuchi & Korsmeyer-Peppas & \\
\hline \multicolumn{7}{|l|}{$\begin{array}{l}\text { Aperture } \\
\text { diameter }(\mu \mathrm{m})\end{array}$} \\
\hline 480 & 59.09 & 0.9934 & 0.8124 & 0.9605 & 0.9981 & 0.9761 \\
\hline 565 & 64.59 & 0.9974 & 0.9967 & 0.9610 & 0.9802 & 0.7316 \\
\hline 700 & 88.43 & 0.9461 & 0.8309 & 0.9869 & 0.9756 & 0.4756 \\
\hline \multicolumn{7}{|l|}{ Weight (\%) } \\
\hline 6.50 & 87.59 & 0.7879 & 0.6425 & 0.8282 & 0.9271 & 0.3866 \\
\hline 8.05 & 64.59 & 0.9974 & 0.9967 & 0.9610 & 0.9802 & 0.7316 \\
\hline
\end{tabular}




\section{CONCLUSION}

EOPs of atenolol were developed based on osmotic technology. The effect of different formulation variables was studied to optimize release profile. The type and amount of osmogen, nature and concentration of plasticizer, the nature of semi-permeable membrane-forming polymer, and aperture diameter were found to control the drug release from the osmotic pumps. Nearly $8.05 \%$ increase in weight of osmotic pumps upon coating with CA was found to attribute desirable release pattern to the osmotic system. The release of the drug was found not affected by the agitational intensity and $\mathrm{pH}$ of the release media. Thus, constant plasma drug levels can be maintained reducing side effects. The zero-order release pattern was further confirmed by mathematical treatment of the in vitro drug release profiles of the optimized formulations and from " $n$ " value, it was found that the drug was released by non-Fickian diffusion mechanism. The formulation produced had sufficient burst strength to withstand the hydrodynamic pressure both in the dissolution media and GI tract.

\section{Financial support and sponsorship}

Nil.

\section{Conflicts of interest}

There are no conflicts of interest.

\section{REFERENCES}

1. Verma RK, Arora S, Garg S. Osmotic pumps in drug delivery. Crit Rev Ther Drug Carrier Syst 2004;21:477-520.

2. Verma RK, Mishra B, Garg S. Osmotically controlled oral drug delivery. Drug Dev Ind Pharm 2000;26:695-708.

3. Theeuwes F, Swanson DR, Guittard G, Ayer A, Khanna S. Osmotic delivery systems for the b-adrenoceptor antagonists metoprolol and oxprenolol: Design and evaluation of systems for once-daily administration. $\mathrm{Br} \mathrm{J}$ Clin Pharmacol 1985;19:69-76.

4. Verma RK, Krishna DM, Garg S. Formulation aspects in the development of osmotically controlled oral drug delivery systems. J Control Release 2002;79:7-27.

5. Fix JA, Dong LC, Pollock C, Shafi KO, Dor PJ, Wong PS. CHRONSET(R) oral osmotic system capabilities and applications. Abs Pap Am Chem Soc 1997;213:233.

6. Breimer DD, Deboer AG. Potential use of osmet - Osmotic pumps in pharmaceutical and pharmacological research in man. Pharmaceutisch Weekblad Sci Ed 1986;8:101.
7. Ritschel WA. Targeting in the gastrointestinal tract: New approaches. Methods Find Exp Clin Pharmacol 1991;13:313-36.

8. Paulis L, Unger T. Novel therapeutic targets for hypertension. Nat Rev Cardiol 2010;7:431-41.

9. Kamp O, Sieswerda GT, Visser CA. Comparison of effects on systolic and diastolic left ventricular function of nebivolol versus atenolol in patients with uncomplicated essential hypertension. Am J Cardiol 2003;92:344-8.

10. Caplar V, Mikotic-Mihun Z, Hoffman H, Kuffinec J, Kajfez F. Atenolol. In: Florey K, editor. Analytical Profiles of Drug Substances. Vol. 13. New York: Academic Press; 1984. p. 1-25.

11. Doodipala N, Palem RC, Reddy S, Rao MY. Pharmaceutical development and clinical pharmacokinetic evaluation of gastro retentive floating matrix tablets of levofloxacin. Int J Pharm Sci Nanotech 2011;4:1463-9.

12. Wald RJ. Modern osmotic tablet technology. Tablets Capsules. Bend Res 2009;7:22-7.

13. Narendar Reddy D, Chinna Reddy P, Sunil R, Madhusudan Rao Y. Development of floating matrix tablets of ofloxacin and ornidazole in combined dosage form: In vitro and in vivo evaluation in healthy human volunteers. Int J Drug Deliv 2012;4:462-9.

14. Bari S, Sathe S, Jain P, Surana S. Spectrophotometric method for simultaneous estimation of atenolol in combination with losartan potassium and hydrochlorothiazide in bulk and tablet formulation. J Pharm Bioallied Sci 2010;2:372-5.

15. Wagner JG. Interpretation of percent dissolved-time plots derived from in vitro testing of conventional tablets and capsules. J Pharm Sci 1969;58:1253-7.

16. Higuchi T. Mechanism of sustained action medication Theoretical analysis of ratelof release of solid drugs dispersed in solid matrices. J Pharm Sci 1963;52:1145-8.

17. Korsmeyer R, Gurny R, Peppas N. Mechanisms of solute release from porous hydrophilic polymers. Int $\mathrm{J}$ Pharm 1983;15:25-35.

18. Peppas NA. Analysis of Fickian and non-Fickian drug release from polymers. Pharm Acta Helv 1985;60:110-1.

19. Kamba M, Seta Y, Kusai A, Ikeda M, Nishimura K. A unique dosage form to evaluate the mechanical destructive forces in the gastrointestinal tract. Int J Pharm 2000;208:61-70.

20. Theeuwes F. Elementary osmotic pump. J Pharm Sci 1975;64:1987-91.

21. Lindstedt B, Ragnarsson G, Hjartstam J. Osmotic pumping as a release mechanism for membrane-coated drug formulations. Int J Pharm 1989;56:261-8.

22. Yuan J, Wu SH. Sustained-release tablets via direct compression: A feasibility study using cellulose acetate and cellulose acetate butyrate. Pharm Technol 2000;24:92-106. 